\title{
Tumor Expression of the Carcinoembryonic Antigen Correlates with High Mitotic Activity and Cell Pleomorphism Index in Lung Carcinoma
}

\author{
Rancés Blanco, ${ }^{1}$ Charles E. Rengifo, ${ }^{2}$ Mercedes Cedeño, ${ }^{2}$ Milagros Frómeta, ${ }^{2}$ \\ Enrique Rengifo, ${ }^{2}$ and Mayra Ramos-Suzarte ${ }^{3}$ \\ ${ }^{1}$ Laboratory of Specific Recognition and Biological Activity, Department of Quality Control, \\ Center of Molecular Immunology, 216 Street and 15 Avenue Atabey, Playa, P.O. Box 16040, 11600 Havana, Cuba \\ ${ }^{2}$ Department of Pathology, Manuel Fajardo General Hospital, Zapata and D Street Vedado, Plaza de la Revolución, \\ 10400 Havana, Cuba \\ ${ }^{3}$ Division of Clinical Trials, Center of Molecular Immunology, 216 Street and 15 Avenue Atabey, Playa, P.O. Box 16040, \\ 11600 Havana, Cuba
}

Correspondence should be addressed to Rancés Blanco; rances@cim.sld.cu

Received 25 March 2013; Accepted 17 May 2013

Academic Editor: Francesco Cappello

Copyright (C) 2013 Rancés Blanco et al. This is an open access article distributed under the Creative Commons Attribution License, which permits unrestricted use, distribution, and reproduction in any medium, provided the original work is properly cited.

At present, some research efforts are focusing on the evaluation of a variety of tumor associated antigens (TAAs) for a better understanding of tumor biology and genetics of lung tumors. For this reason, we evaluated the tissue expression of carcinoembryonic antigen (CEA) and ior C2 (a cell surface O-linked glycoprotein carbohydrate chain TAA) in lung carcinomas, as well as its correlation with a variety of clinicopathological features. The tissue expression of CEA was evidenced in 22/43 (51.16\%) lung carcinomas and it was correlated with mitotic activity, cell pleomorphism indexes, and age of patients. The expression of ior C2 was observed in 15/43 (34.88\%) tumors but no correlation with the clinicopathological features mentioned above was obtained. No correlation between both CEA and ior C2 antigens expression and the overall survival (OS) of non-small-cell lung cancer patients was also observed. However, CEA-negative patients displayed higher OS rates as compared with positive ones (69.74 versus 58.26 months). Our results seem to be in agreement with the role of CEA expression in tumor cell proliferation, inhibition of cell polarizations and tissue architecture distortion. The significance of ior C2 antigen in these malignancies and it potential use in diagnosis, prognosis, and/or immunotherapy must be reevaluated.

\section{Introduction}

Lung tumors are one of the leading causes of cancer-related mortality around the world [1]. There are two main variants of the disease, non-small cell lung cancer (NSCLC) and smallcell lung cancer (SCLC). However, NSCLC represents more than $80 \%$ of all lung carcinomas [2]. In patients with NSCLC, some genetic and regulatory abnormalities have been considered responsible for the tumor survival advantage. The alterations in gene expression that occur in cells during the malignant transformation usually conduce to the aberrant expression of antigens whether existing or not in normal cells. In this way, some research efforts are focusing on the evaluation of a variety of tumor associated antigens (TAAs) for a better understanding of tumor biology and genetics of lung tumors [3].

Carcinoembryonic antigen (CEA) is a glycoprotein expressed during embryonic and fetal development. It is frequently expressed on the apical surface of gastrointestinal epithelium, although it can also be found in other human epithelium, including lung tissues $[4,5]$. Serum expression of CEA has been considered a sensitive and valuable tumor marker for diagnosis, prognosis, and therapy monitoring in lung cancer $[6,7]$. Nevertheless, up to now, the evaluation 
of CEA expression has been mainly restricted to the serum analysis [6-9] and the function of tumor CEA expression has remained unelucidated [10].

On the other hand, the ior C2 is an O-linked-tumorspecific glycoprotein with very limited presence in most normal tissues and overexpressed in the surface of some human malignancies. This TAA was demonstrated in these malignancies using the ior C5 Mab, a highly specific IgG1 against ior C2 antigen, by means of immunohistochemical methods [11, 12]. Additionally, immunoscintigraphy with 99mTc-labeled Mab ior C5 has been considered a useful procedure for the diagnosis and followup of the patients with colorectal tumors, its metastasis, and recurrences [13-17].

In the present work, we evaluated the tissue expression of CEA and ior C2 antigens in lung carcinoma, as well as its correlation with a variety of clinicopathological features such as mitotic activity index, cell pleomorphism, and overall survival of patients.

\section{Materials and Methods}

2.1. Monoclonal Antibodies. We used the ior ceal [18] and ior C5 [12] Mabs, both obtained and produced by the Center of Molecular Immunology (Havana, Cuba). These Mabs are two murine IgG1 highly specific against the carcinoembryonic and a cell surface O-linked glycoprotein carbohydrate chain (ior C2) antigens, respectively.

2.2. Tissue Specimens and Previous Processing. A number of 43 routinely processed, formalin-fixed, and paraffinembedded archival samples with diagnosis of lung cancer were obtained from the pathology department of the National Institute of Oncology and Radiobiology. The samples were taken after obtaining the approval consent by the institutional ethical committee. Five micrometer serial sections from each block were obtained in a micrometer (Leitz 1512, Germany) and mounted on plus slides (Dako S2024, Carpinteria, CA, USA). All sections were attached to the slide by heating in a $70^{\circ} \mathrm{C}$ oven for $1 \mathrm{~h}$. Afterward, the slides were kept at room temperature until they were used.

2.3. Immunohistochemical Staining. The slides were dewaxed in xylene and rehydrated in decreasing ethanol series as usual and endogenous peroxidase activity was blocked with $0.03 \%$ hydrogen peroxide in methanol for 30 minutes at room temperature. Afterward all sections were washed in distilled water for 10 minutes, then were rinsed with TBS (Tris/saline buffer solution) for 5 minutes, were placed in a humid chamber, and incubated with the primary mouse ior ceal and ior C5 Mabs for $1 \mathrm{~h}$ at room temperature. Negative controls were performed by substituting primary antibody for TBS and sections of colonic adenocarcinoma of known positivity for these antigens were taken as positive control. After two rinses in TBS, the slides were incubated with a rabbit anti-mouse biotinylated secondary antibody (Dako E0354, Carpinteria, CA, USA) and ABComplex/HRP (Dako E0355, Carpinteria, CA, USA) both for 30 minutes at room temperature dilution $1: 100$. Between incubations, slides were washed with TBS for 10 minutes. Afterward, enzymatic activity was visualized with DAB substrate chromogenic solution (Dako K3465, Carpinteria, CA, USA) and the tissues were counterstained with Mayer's hematoxylin (Dako S2020, Carpinteria, CA, USA). The samples were dehydrated and mounted with a synthetic medium.

2.4. Immunohistochemical Evaluation. The presence of brown staining (DAB reaction product) on both cell membrane and cytoplasm of malignant cells was considered as positive reactivity for ior ceal and ior C5 Mabs. Sections only stained with Mayer's hematoxylin (blue color) were taken as negative.

All evaluations were performed using an Olympus BX51 brightfield microscope with magnification of 200x and 400x (10x ocular with $20 \mathrm{x}$ and $40 \mathrm{x}$ objectives, resp.). The intensity of reaction of each tumor tissues was qualitatively estimated and expressed as follows: negative $(-)$, weak $(+)$, moderate $(++)$, and intense $(+++)$. A combination of these patterns was used to express intermediate levels of immunostaining. The most representative regions of each section were selected and the percentage of tumor cells stained with Mabs in them was estimated using the $10 \mathrm{x}$ objective lens (100x magnification). It was classified as 0 (negative to less than 5\%), 1 (6\%-50\%), and 2 (more than 50\%). All microscopic analyses were performed by two different observers.

2.5. Pathological Features Evaluation. The evaluation of some pathological features was performed for each tumor tissues using the hematoxylin and eosin (HE) staining. Morphologic parameters such as histopathological classification, grade of differentiation, and degree of cellular pleomorphism as well as mitotic and necrosis indexes were evaluated for an expert pathologist (Charles E. Rengifo) as previously described in [19]. Briefly, the degree of cell pleomorphism was expressed by the evaluation of some cytomorphologic characteristics such as cell and nuclear size, cellular shape, chromatin pattern, nucleoli, and amount of cytoplasm and was scored as follows: 0 (no evident cell pleomorphism) 1 (low), 2 (moderate), and 3 (high) cell pleomorphism.

For the mitotic activity index (MAI), the most cellular area of each tumor section (containing the subjectively highest number of mitoses) was selected. Then, only unequivocal mitotic figures were counted in 10 high-power fields with 400x magnification (10x ocular, 40x objective) of each sample. Finally, the MAI was calculated by dividing mitotic cells out of total cells counted and expressed as previously described for cell pleomorphism.

In the case of the degree of tumor necrosis (necrosis index), a low-power field with 100x magnification (10x ocular, $10 \mathrm{x}$ objective) of each section was used. It was scored subjectively as follows: 0 (no necrosis), 1 (less than $50 \%$ of necrosis areas per field), and 2 (more than $50 \%$ of necrosis areas per field).

2.6. Statistical Analysis. GraphPad Prism 5 software (2007 GraphPad Software Inc., La Jolla, CA, USA) was used for data analysis. The correlation between the reactivity of both ior 


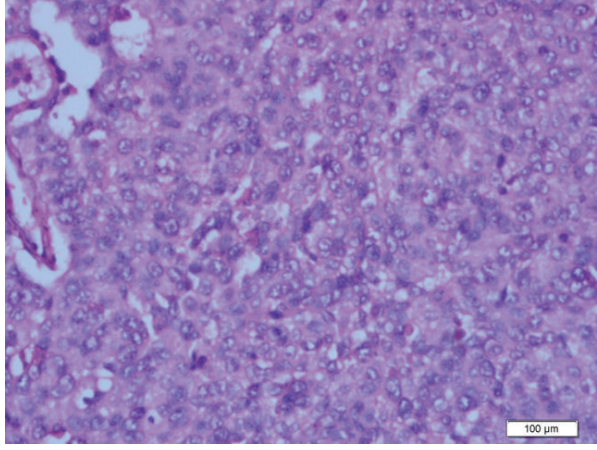

(a)

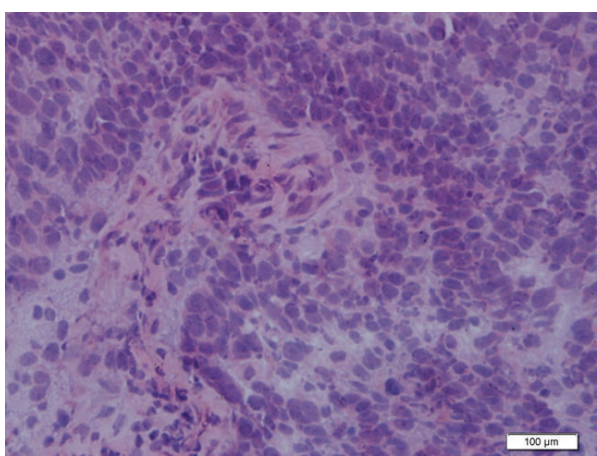

(c)

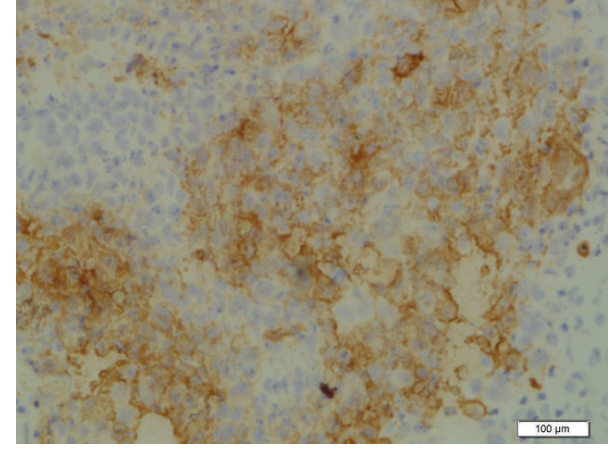

(b)

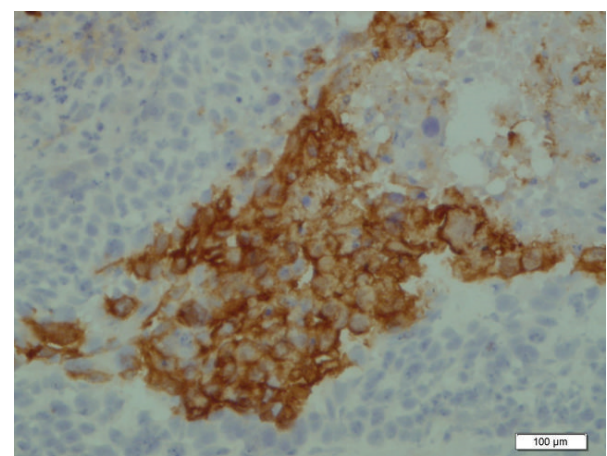

(d)

FIGURE 1: Microphotographs of lung squamous cell carcinomas sections. (a) and (c) represent hematoxylin and eosin staining. Vote malignant cells exhibiting a moderate mitotic activity index and high degree of cell pleomorphism, respectively. (b) and (d) represent tissue detection of CEA antigen. Note the moderate (b) and intense (d) reactivity of ior ceal Mab. The reactivity of this Mab was mainly located in the membrane and also in the cytoplasm of malignant cells. White bar $=100 \mu \mathrm{m}$.

ceal and ior C5 Mabs with clinical and pathological features was assessed by Spearman ranks correlation coefficients. Survival distribution was estimated by the Kaplan-Meier method. Survival comparison was performed by two-sided logrank tests. For all tests, $P<0.05$ was considered statistically significant.

\section{Results}

3.1. Patient Description and Pathological Features. Tables 1 and 2 showed a summary of patient characteristics and some pathological features. The gender ratio was close to $2: 1$ in favor of males. The median of patient age at presentation was 55.58 years (ranged from 23 to 76 years). Median overall survival of patients was 65.55 months (ranged from 3 to 93.0 months) and 35.02 months for NSCLC and SCLC, respectively.

3.2. High Tumor Expression of CEA Was Evidenced in Lung Tumors. The tissue expression of CEA was evidenced in $22 / 43$ (51.16\%) lung carcinomas (Table 3 ). In 15/22 (68.18\%) of tumors, a weak or focal reaction located in both cell clusters and its secretion with ior ceal Mab was detected, while in $6 / 22(27.27 \%)$ of samples a moderate-to-intense staining with this Mab was observed. In the latter, the pattern of staining of ior ceal Mab was finely granular and was highly expressed in both the plasmatic membrane and the cytoplasm of malignant cells (Figure 1).

3.3. CEA Expression Correlates with Age of Patient, High Mitotic Activity Index, and Cell Pleomorphism in Lung Carcinoma. A significant correlation was detected between the tissue expression of CEA and both MAI $(P=0.0218$, rs $=0.3489$; Spearman test $)$ and pleomorphism index $(P=$ $0.0159, \mathrm{rs}=0.3655$; Spearman test). In addition, the expression of CEA correlates with the age of patients $(P=0.0497$, rs $=-0.3012$; Spearman test). No correlation between CEA expression and the rest of the clinicopathological features was observed.

3.4. The Expression of Ior C2 Antigen Was Limited in Lung Tumors. The expression of ior C2 antigen was observed in $15 / 43(34.88 \%)$ lung tumors and was mainly localized in cell clusters and its secretion (score 1). According to the histopathological classification, 4/14 (28.57\%) squamous cell carcinoma, 5/14 (25.71\%) adenocarcinoma, and 3/9 (33.33\%) large cell carcinoma as well as $2 / 4(50.00 \%)$ of other minor types represented were recognized by the ior C5 Mab (Figure 2). The reactivity of ior C5 Mab was also evidenced in $2 / 2$ of SCLC.

No correlation between the expression of ior C2 antigen and the clinicopathological features was obtained. 
TABLE 1: Patients characteristics.

\begin{tabular}{lc}
\hline Features & Number $(\%)(n=43)$ \\
\hline Gender & \\
Female & $15(34.88)$ \\
Male & $28(65.12)$ \\
Age (years) & \\
$\quad<60$ & $31(72.09)$ \\
$60-70$ & $9(20.93)$ \\
$>70$ & $3(6.98)$ \\
Tumor size (cm) & \\
$<3$ & $7(16.28)$ \\
$>3$ & $36(83.72)$ \\
Tumor stage & \\
LD & $1(2.32)$ \\
I & $24(55.81)$ \\
II & $8(18.60)$ \\
III A & $5(11.63)$ \\
III B & $2(4.65)$ \\
IV & $3(6.98)$ \\
Recurrence & \\
Yes & $36(83.72)$ \\
No & $7(16.28)$ \\
Overall survival & \\
Alive & $33(76.74)$ \\
Dead & $10(23.26)$ \\
Median (months) & 63.07 \\
\hline
\end{tabular}

Legend: no.: number of cases; \%: percentages; LD: limited disease.

3.5. Relationship between Antigens Expression and Overall Survival of Patients. No correlation between both CEA and ior $\mathrm{C} 2$ antigens overexpression and the overall survival of NSCLC patients was observed $(P=0.1772$ and $P=0.5043$; logrank test, resp.) (Figures 3 and 4). However, CEA-negative patients displayed higher overall survival rates as compared with positive ones (69.74 versus 58.26 months).

\section{Discussion}

Despite the recent advances in lung cancer therapy, this disease still has a very poor prognosis, representing one of the leading causes of cancer-related mortality worldwide [1]. For that reason, the identification of prognostic factors, including tumor markers, clinicopathological indicators and genetic alterations, is of the utmost importance for patients with lung cancer [3].

The overexpression of CEA has been reported in 30\%$70 \%$ of patients with NSCLC and was most frequently observed in patients with adenocarcinoma and advanced stage carcinoma [20]. In this study, we showed the tissue reactivity of ior ceal Mab, a murine IgG1 highly specific raised against carcinoembryonic antigen, in about the half of lung cancer sections evaluated. The pattern of staining with this Mab was finely granular and was localized in both, cell membrane and cytoplasm of malignant epithelial cells.
TABLE 2: Tumor characteristics.

\begin{tabular}{|c|c|}
\hline Features & Number $(\%)(n=43)$ \\
\hline \multicolumn{2}{|l|}{ Histopathological type } \\
\hline Small-cell lung carcinoma & $2(4.65)$ \\
\hline \multicolumn{2}{|l|}{ Non-small cell lung carcinoma } \\
\hline Squamous cell carcinoma & $14(32.56)$ \\
\hline Adenocarcinoma & $14(32.56)$ \\
\hline Large cell carcinoma & $9(20.93)$ \\
\hline Other & $4(9.30)$ \\
\hline \multicolumn{2}{|l|}{ Grade of differentiation } \\
\hline Well & $5(11.63)$ \\
\hline Moderate & $18(41.86)$ \\
\hline Poor & $15(34.88)$ \\
\hline Undifferentiated & $5(11.63)$ \\
\hline \multicolumn{2}{|l|}{ Degree of cell pleomorphism } \\
\hline No evident & $1(2.33)$ \\
\hline Low & $22(51.16)$ \\
\hline Moderate & $12(27.91)$ \\
\hline High & $8(18.60)$ \\
\hline \multicolumn{2}{|l|}{ Necrosis index } \\
\hline No evident & $17(39.53)$ \\
\hline$<50 \%$ & $15(34.88)$ \\
\hline$>50 \%$ & $11(25.58)$ \\
\hline \multicolumn{2}{|l|}{ Mitotic index } \\
\hline No evident & $3(6.98)$ \\
\hline Low & $13(30.23)$ \\
\hline Moderate & $18(41.86)$ \\
\hline High & $9(20.93)$ \\
\hline
\end{tabular}

Legend: no.: number of cases; \%: percentages.

A similar immunohistochemical result using a different antiCEA Mab was previously described [10]. Moreover, the in vivo tissue reactivity of ior ceal Mab labelled with $99 \mathrm{mTc}$ was demonstrated in both primary and metastatic colorectal carcinoma by the radioimmunoscintigrafic technique $[16,17$, 21].

Several studies have shown that high CEA levels are a potential marker of poor prognosis in NSCLC regardless of treatment $[6,20]$. Meanwhile, the determination of which amount of tissue CEA expression in lung tumors has clinical and/or biological relevance still remains unclear [10]. We obtained no differences between CEA tissue expression and overall survival of patients. Although, patients with high CEA expression displayed lower overall survival rates as compared with negative ones. In this way, the potential prognostic value of ior ceal Mab reactivity in NSCLC should be evaluated using a higher number of cases.

It is known that CEA is a cell surface adhesion protein related with the cell-to-cell adhesion [22], blocking cell differentiation effects and cellular transformation [23]. Additionally, the antiapoptotic effects of CEA expression in cancer cells have been demonstrated [24].

The overexpression of CEA has been considered to be directly related to the tumor aggressive behavior $[8,25]$. Here, we found that high levels of CEA expression correlate with 
TABLE 3: Immunohistochemical expression of CEA.

\begin{tabular}{lccc}
\hline Histopathological type & 0 & H-score & 1 \\
& Number of cases (\%) & Number of cases (\%) & $\begin{array}{c}2 \\
\text { Number of cases (\%) }\end{array}$ \\
\hline SCLC & 0 & $1 / 2(50.00)$ & $1 / 2(50.00)$ \\
NSCLC & & & $3 / 14(21.43)$ \\
Squamous cell carcinoma & $5 / 14(35.71)$ & $6 / 14(42.86)$ & $1 / 14(7.14)$ \\
Adenocarcinoma & $9 / 14(64.29)$ & $4 / 14(28.57)$ & $1 / 9(11.11)$ \\
Large cell carcinoma & $6 / 9(66.67)$ & $2 / 9(22.22)$ & 0 \\
Other & $2 / 4(50.00)$ & $2 / 4(50.00)$ & \\
\hline
\end{tabular}

Legend: SCLC: small cell-lung cancer; NSCLC: non-small cell lung cancer; \%: percentages; 0: negative; 1: (6\%-50\%) and 2: (more than 50\%).

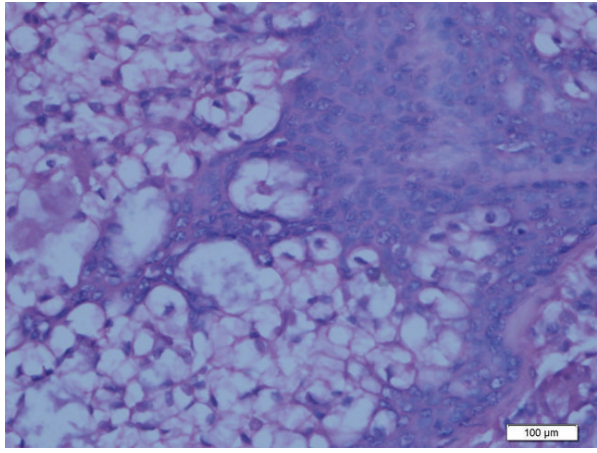

(a)

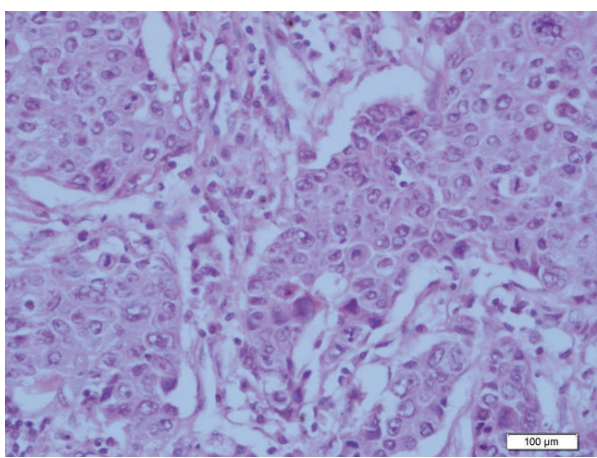

(c)

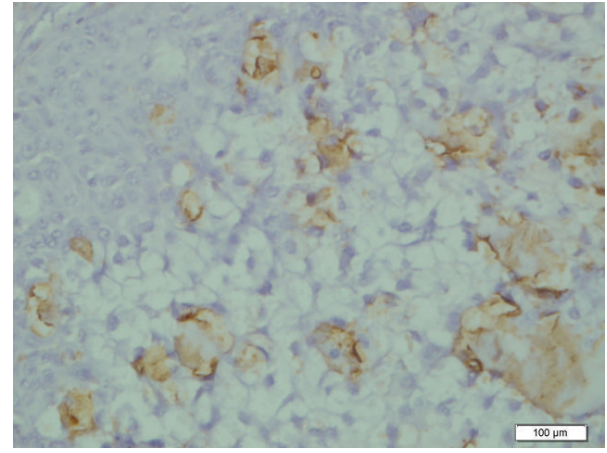

(b)

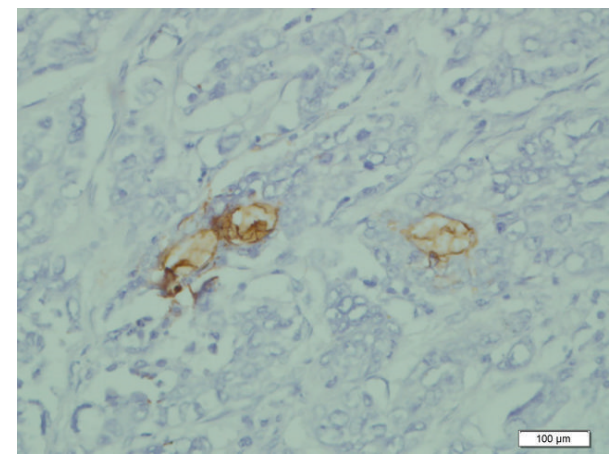

(d)

FIGURE 2: Hematoxylin and eosin staining of lung adenocarcinoma (a) and mucoepidermoid carcinoma (c) sections. Note: malignant cells exhibiting a moderate degree of cell pleomorphism and high mitotic activity index, respectively. (b) and (d) represent tissue detection of C2 antigen. Note the moderate reactivity of ior C5 Mab mainly located in cell secretion and cell clusters, respectively. White bar $=100 \mu \mathrm{m}$.

an increase in tumor cell proliferation measured by means of mitotic activity index. In previous studies, the expression of CEA in the proliferative phase of the human colonocytes cell cycle has been reported to be limited [26]. Nevertheless, induced constitutive expression of CEA at all phases of the growth cycle, as in most of colorectal carcinomas [27], has been related to the appearance of dramatic tumorigenic effects [26].

Previously, it was demonstrated that CEACAM6, a closely related family member of CEA, is able to induce lung cells proliferation, probably by interfering with the contactinhibiting signal, leading to undifferentiated anchorageindependent cell growth [28]. In the present work, we obtained a correlation between CEA expression and the degree of cell pleomorphism measured by the evaluation of some cytomorphologic characteristics. Deregulated overexpression of CEA in human cells that remain potential division and have not yet differentiated can decrease the cellular differentiation, block cellular polarization, and distort normal cellular architecture both in vitro and in vivo [26].

In previous studies, little differences in the biological behavior of NSCLC in older and younger individuals have been reported [29]. In this way, molecular phenotypic studies have been suggested to investigate this controversial topic [30]. Here, we found that younger patients exhibited high 


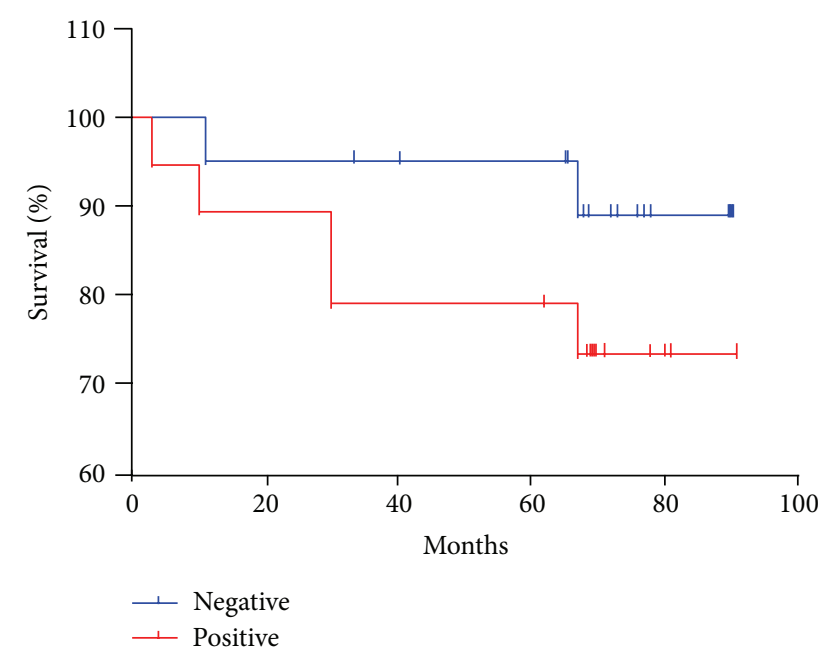

FIGURE 3: Kaplan-Meier estimate of overall survival among NSCLC patients showing different levels of tissue CEA expression $(P=$ 0.1772; logrank test).

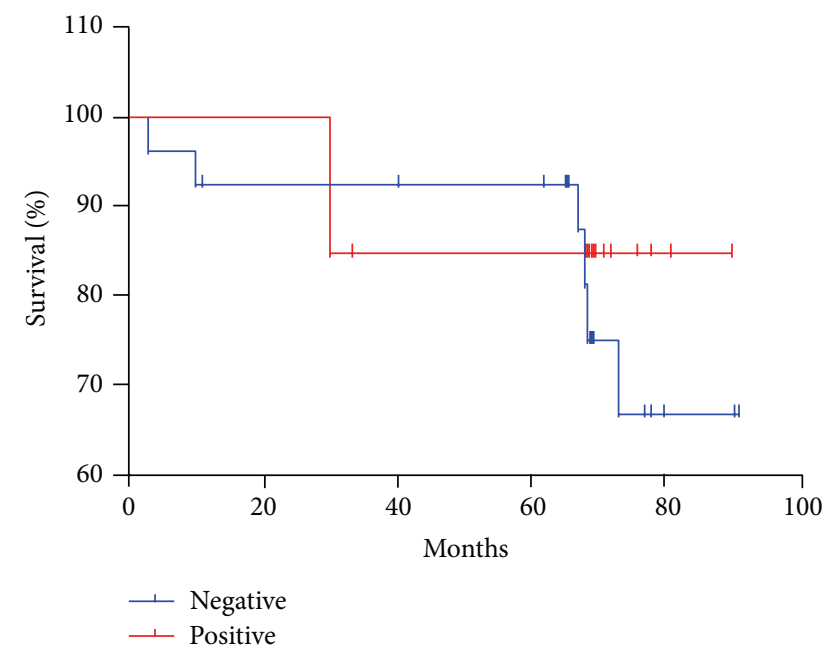

FIGURE 4: Kaplan-Meier estimate of overall survival among NSCLC patients showing different levels of tissue expression of ior C2 antigen $(P=0.5043$; logrank test).

level of tissue CEA expression as compared with older patients. These results are in agreement with the suggestion that younger NSCLC patients generally display a more accelerated growth and progress than that in older patients [31]. However, NSCLC had been considered a similar entity in older and younger individuals, since the same clinicopathological prognostic factors were valid in both age groups $[29,30]$.

Our results seem to be in agreement with the important role of tissue CEA expression in lung tumor biology, although no correlation of CEA expression and some pathological features such as tumor size, tumor state, and recurrence was evidenced.
On the other hand, the ior C5 Mab is a murine IgG1 that recognizes the TAA ior $\mathrm{C} 2$. This antigen is a cell surface $\mathrm{O}$ linked glycoprotein carbohydrate chain very limited in most normal tissues and heterogeneously expressed in a variety of human malignancies such as ovary, breast, uterus, and lung tumors, although it was mostly evidenced in colorectal tumors $[12,32]$. In primary and metastatic colorectal carcinomas as well as in ovarian adenocarcinomas, these results were confirmed by immunoscintigraphy technique with ior C5 Mab labeled with 99mTc-labeled [13-17, 33].

In lung tumors, the expression of ior $\mathrm{C} 2$ antigen was only restricted to adenocarcinomas $[12,32]$. In the present work, the tissue reactivity of ior C5 Mab was detected in about the $35 \%$ of lung carcinomas, not taking into account the histopathological classification. Curiously, the staining with this Mab was mostly evidenced in SCLC. The pattern of recognition was finely granular and was located in both epithelial cells and its secretion, similar to that described in $[12,32]$.

In spite of the expression of the ior $\mathrm{C} 2$ antigen in tumors that has been demonstrated, to our knowledge the clinical and/or biological significance in lung cancer still remains unclear. Unfortunately, in this study we obtained no correlation between ior $\mathrm{C} 2$ antigen expression and the overall survival of patients neither with the rest of the clinicopathological features assessed. In this way, a higher series of lung tumors must be evaluated in order to explore the role of ior C2 antigen in these malignancies, as well as its potential use in diagnosis, prognosis, and/or immunotherapy.

\section{Conclusions}

In summary, we reported the tissue expression of CEA antigen by means of ior ceal Mab, in both SCLC and NSCLC. The correlation of CEA expression with age of patient, high mitotic activity index, and the degree of cell pleomorphism was also demonstrated. Our results seem to be in agreement with the role of CEA expression in tumor cell proliferation as well as in the inhibition of cell polarization and the distortion of tissue architecture. Additionally, we showed the immunohistochemical expression of ior C2 antigen, a cell surface O-linked glycoprotein carbohydrate chain, in the same system. However, no correlation between ior $\mathrm{C} 2$ antigen expression and the overall survival of patients neither with the rest of the clinicopathological features was obtained. In this way, the significance of ior $\mathrm{C} 2$ antigen for lung tumors biological behavior still remains unclear.

\section{Conflict of Interests}

The authors report no conflict of interests.

\section{Authors' Contribution}

Rancés Blanco and Charles E. Rengifo contributed equally to this work. 


\section{Acknowledgments}

The authors are grateful to Idania Suárez López-Gavilán B.Sc., for the editorial assistance. Financial support was provided by the Center of Molecular Immunology.

\section{References}

[1] K. Kaira, N. Oriuchi, N. Sunaga, T. Ishizuka, K. Shimizu, and N. A. Yamamoto, "Systemic review of PET and biology in lung cancer," American Journal of Translational Research, vol. 3, no. 4, pp. 383-391, 2011.

[2] G. Giaccone and P. A. Zucali, "Src as a potential therapeutic target in non-small-cell lung cancer," Annals of Oncology, vol. 19, no. 7, pp. 1219-1223, 2008.

[3] E. Blanchard, "Targeted agents in non small cell lung cancer," Cancer Therapy, vol. 6, pp. 95-102, 2008.

[4] K. Kuespert, S. Pils, and C. R. Hauck, "CEACAMs: their role in physiology and pathophysiology," Current Opinion in Cell Biology, vol. 18, no. 5, pp. 565-571, 2006.

[5] N. Kokkonen, I. F. Ulibarri, A. Kauppila et al., "Hypoxia upregulates carcinoembryonic antigen expression in cancer cells," International Journal of Cancer, vol. 121, no. 11, pp. 24432450, 2007.

[6] M. Okada, W. Nishio, T. Sakamoto et al., "Prognostic significance of perioperative serum carcinoembryonic antigen in nonsmall cell lung cancer: analysis of 1,000 consecutive resections for clinical stage I disease," Annals of Thoracic Surgery, vol. 78, no. 1, pp. 216-221, 2004.

[7] R. Molina, J. M. Auge, J. M. Escudero et al., "Mucins CA 125, CA 19.9, CA 15.3 and TAG-72.3 as tumor markers in patients with lung cancer: comparison with CYFRA 21-1, CEA, SCC and NSE," Tumor Biology, vol. 29, no. 6, pp. 371-380, 2009.

[8] H. Matsuguma, R. Nakahara, S. Igarashi et al., "Pathologic stage I non-small cell lung cancer with high levels of preoperative serum carcinoembryonic antigen: clinicopathologic characteristics and prognosis," Journal of Thoracic and Cardiovascular Surgery, vol. 135, no. 1, pp. 44-49, 2008.

[9] M. Jung, S. H. Kim, Y. J. Lee et al., "Prognostic and predictive value of carcinoembryonic antigen and cytokeratin-19 fragments levels in advanced non-small cell lung cancer patients treated with gefitinib or erlotinib," Yonsei Medical Journal, vol. 53, no. 5, pp. 931-939, 2012.

[10] J. Wang, Y. Ma, Z. H. Zhu, D. R. Situ, Y. Hu, and T. H. Rong, "Expression and prognostic relevance of tumor carcinoembryonic antigen in stage IB non-small cell lung cancer," Journal of Thoracic Disease, vol. 4, no. 5, pp. 490-496, 2012.

[11] A. M. Vazquez, B. Tormo, A. Velandia et al., "Characterization of the colorectal antigen IOR-C2," Hybridoma, vol. 11, no. 2, pp. 245-256, 1992.

[12] A. M. Vazquez, B. R. Tormo, M. Alfonso et al., "Characterization of ior C5 colorectal tumor associated antigen," Inmunologia, vol. 14, no. 3, pp. 130-132, 1995.

[13] N. Iznaga-Escobar, M. Ramos-Suzarte, A. Morales-Morales, L. Torres-Arocha, N. Rodríguez-Mesa, and R. Pérez-Rodríguez, "99mTc-labeled murine ior C5 monoclonal antibody in colorectal carcinoma patients: pharmacokinetics, biodistribution, absorbed radiation doses to normal organs and tissues and tumor localization," Methods and Findings in Experimental and Clinical Pharmacology, vol. 26, no. 9, pp. 687-696, 2004.

[14] N. Iznaga-Escobar, M. Ramos-Zusarte, A. Morales-Morales, G. Núñez-Gandolff, and R. Pérez-Rodríguez, "99mTc-ior C5: diagnostic for colorectal cancer," Drugs of the Future, vol. 29, no. 2, pp. 127-135, 2004.

[15] M. Ramos-Suzarte, A. P. Pintado, N. R. Mesa et al., "Diagnostic efficacy and safety of $99 \mathrm{mTc}$-labeled monoclonal antibody Ior c5 in patients with colorectal and anal carcinomas: final report clinical trial phase I/II," Cancer Biology and Therapy, vol. 6, no. 1, pp. 22-29, 2007.

[16] M. Ramos-Suzarte, Inmunogammagrafía de Tumores de Origen Epitelial, Académica Española, 2012.

[17] M. Ramos-Suzarte, N. Rodríguez-Mesa, and J. Perfecto-Oliva, Inmunogammagrafía con los AcM ior c5 e Ior Ceal en Cáncer Colorrectal. Tumores Primarios, Metástasis y Recidivas, Editorial Académica, 2013.

[18] J. V. Gavilondo, A. M. Vázquez, S. Fong et al., "Anticuerpos monoclonales contra el antígeno carcinoembrionario en ensayos inmunohistoquímicos e inmunocitoquímicos," Interferón Y Biotecnología, vol. 4, no. 2, pp. 143-156, 1987.

[19] R. Blanco, C. E. Rengifo, M. Cedeño, M. Frómeta, E. Rengifo, and A. Carr, "Immunoreactivity of the 14F7 Mab (raised against $\mathrm{N}$-glycolyl GM3 ganglioside) as a positive prognostic factor in non-small cell lung cancer," Pathology Research International, vol. 2012, Article ID 235418, 12 pages, 2012.

[20] K. Matsuoka, S. Sumitomo, N. Nakashima, D. Nakajima, and N. Misaki, "Prognostic value of carcinoembryonic antigen and CYFRA21-1 in patients with pathological stage I non-small cell lung cancer," European Journal of Cardio-Thoracic Surgery, vol. 32, no. 3, pp. 435-439, 2007.

[21] R. Sirisriro, V. Boonkitticharoen, P. Kraiphibul et al., "Detection of colorectal carcinoma by anti-CEA monoclonal antibody (IOR-CEA1) labeled with (99m)Tc scintigraphy," HepatoGastroenterology, vol. 47, no. 32, pp. 405-413, 2000.

[22] S. Benchimol, A. Fuks, S. Jothy, N. Beauchemin, K. Shirota, and C. P. Stanners, "Carcinoembryonic antigen, a human tumor marker, functions as an intercellular adhesion molecule," Cell, vol. 57, no. 2, pp. 327-334, 1989.

[23] R. A. Screaton, L. Z. Penn, and C. P. Stanners, "Carcinoembryonic antigen, a human tumor marker, cooperates with Myc and Bcl-2 in cellular transformation," Journal of Cell Biology, vol. 137, no. 4, pp. 939-952, 1997.

[24] C. Ordoñez, R. A. Screaton, C. Ilantzis, and C. P. Stanners, "Human carcinoembryonic antigen functions as a general inhibitor of anoikis," Cancer Research, vol. 60, no. 13, pp. 3419$3424,2000$.

[25] S. Hammarström, "The carcinoembryonic antigen (CEA) family: structures, suggested functions and expression in normal and malignant tissues," Seminars in Cancer Biology, vol. 9, no. 2, pp. 67-81, 1999.

[26] C. Ilantzis, L. Demarte, R. A. Screaton, and C. P. Stanners, "Deregulated expression of the human tumor marker CEA and CEA family member CEACAM6 disrupts tissue architecture and blocks colonocyte differentiation," Neoplasia, vol. 4, no. 2, pp. 151-163, 2002.

[27] W. Hauck and C. P. Stanners, "Control of carcinoembryonic antigen gene family expression in a differentiating colon carcinoma cell line, Caco-2," Cancer Research, vol. 51, no. 13, pp. 3526-3533, 1991.

[28] B. B. Singer, I. Scheffrahn, R. Kammerer, N. Suttorp, S. Ergun, and H. Slevogt, "Deregulation of the CEACAM expression pattern causes undifferentiated cell growth in human lung adenocarcinoma cells," PLoS ONE, vol. 5, no. 1, Article ID e8747, 2010. 
[29] A. Koumarianou, G. Fountzilas, P. Kosmidis et al., "Non small cell lung cancer in the elderly: clinico-pathologic, management and outcome characteristics in comparison to younger patients," Journal of Chemotherapy, vol. 21, no. 5, pp. 573-583, 2009.

[30] D. Mauri, G. Pentheroudakis, D. Bafaloukos et al., "Non-small cell lung cancer in the young: a retrospective analysis of diagnosis, management and outcome data," Anticancer Research, vol. 26, no. 4, pp. 3175-3182, 2006.

[31] H. Minami, M. Yoshimura, H. Matsuoka, S. Toshihiko, and N. Tsubota, "Lung cancer treated surgically in patients $<50$ years of age," Chest, vol. 120, no. 1, pp. 32-36, 2001.

[32] M. Cedeño, C. E. Rengifo, M. Ramos-Suzarte, R. Blanco, E. Rengifo, and F. Nogales, "IOR C2: a tumor associated antigen as potential target for immunotherapy in epithelial ovarian cancer," Acta Microscópica, vol. 22, no. 3, 2013.

[33] M. E. Solano, A. Perera, J. F. Batista et al., "Immunoscintigraphic diagnosis of Ovarian Cancer with Tc-99m labeled MAb ior-c5: first Clinical Results," World Journal of Nuclear Medicine, vol. 2, pp. 30-36, 2003. 

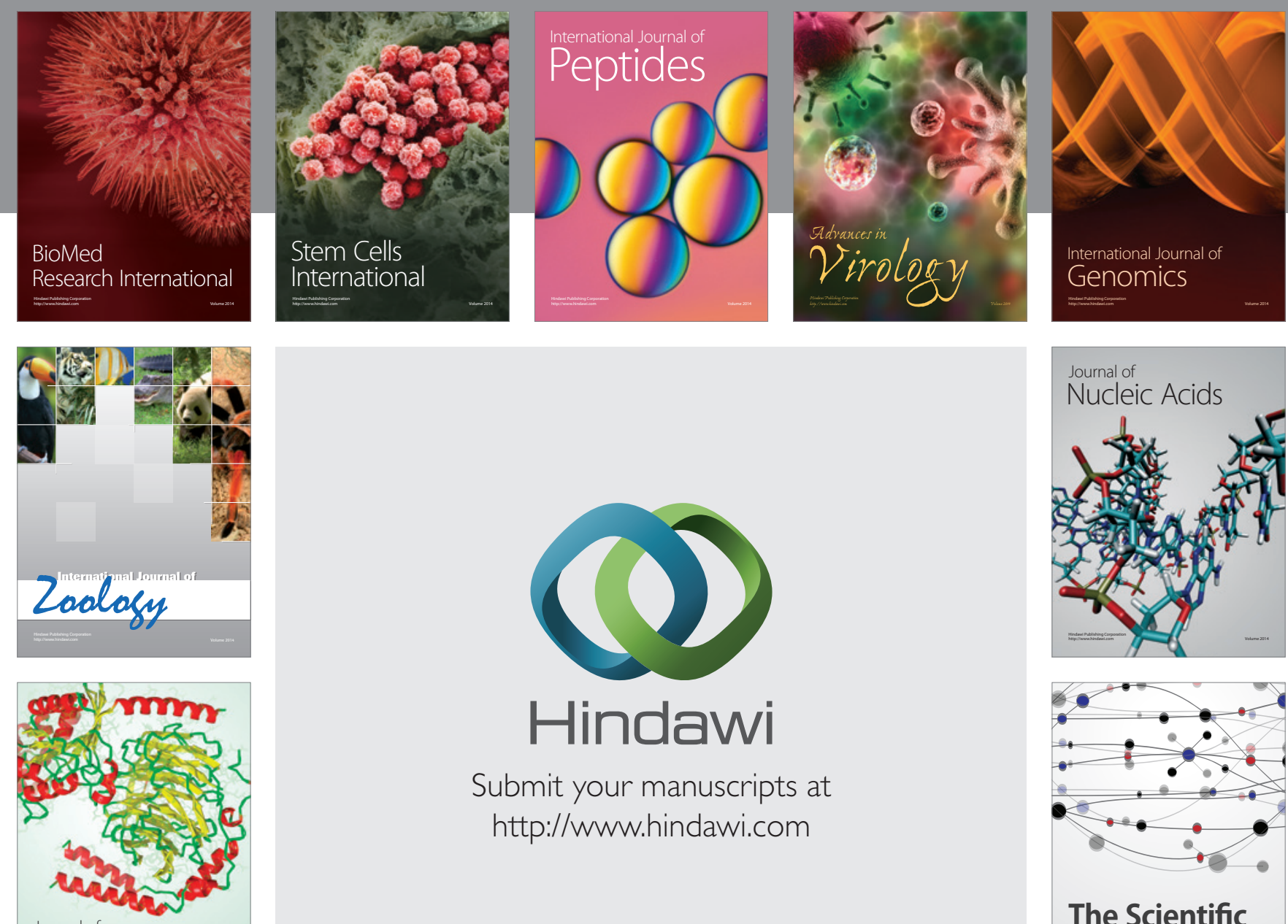

Submit your manuscripts at

http://www.hindawi.com

Journal of
Signal Transduction
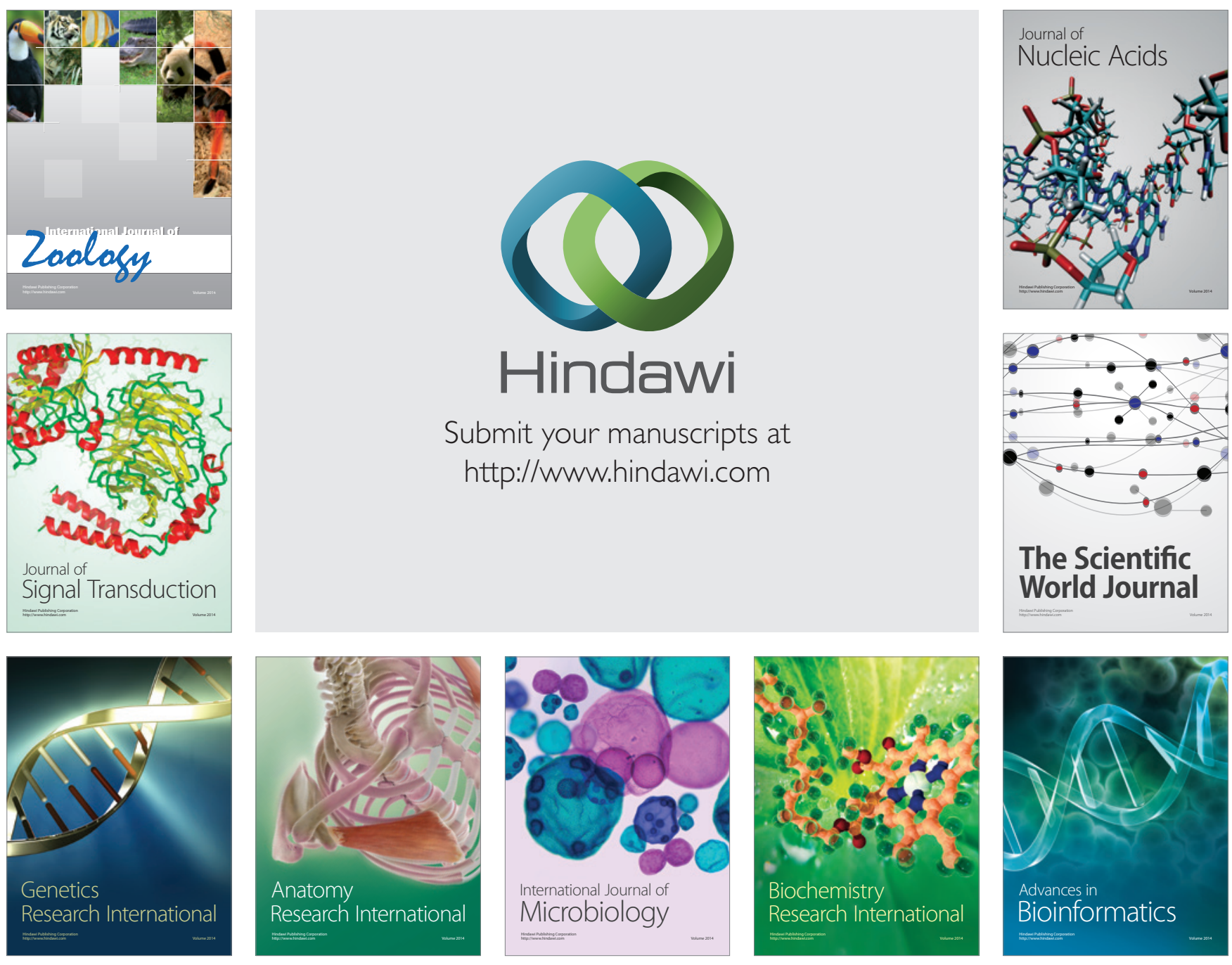

The Scientific World Journal
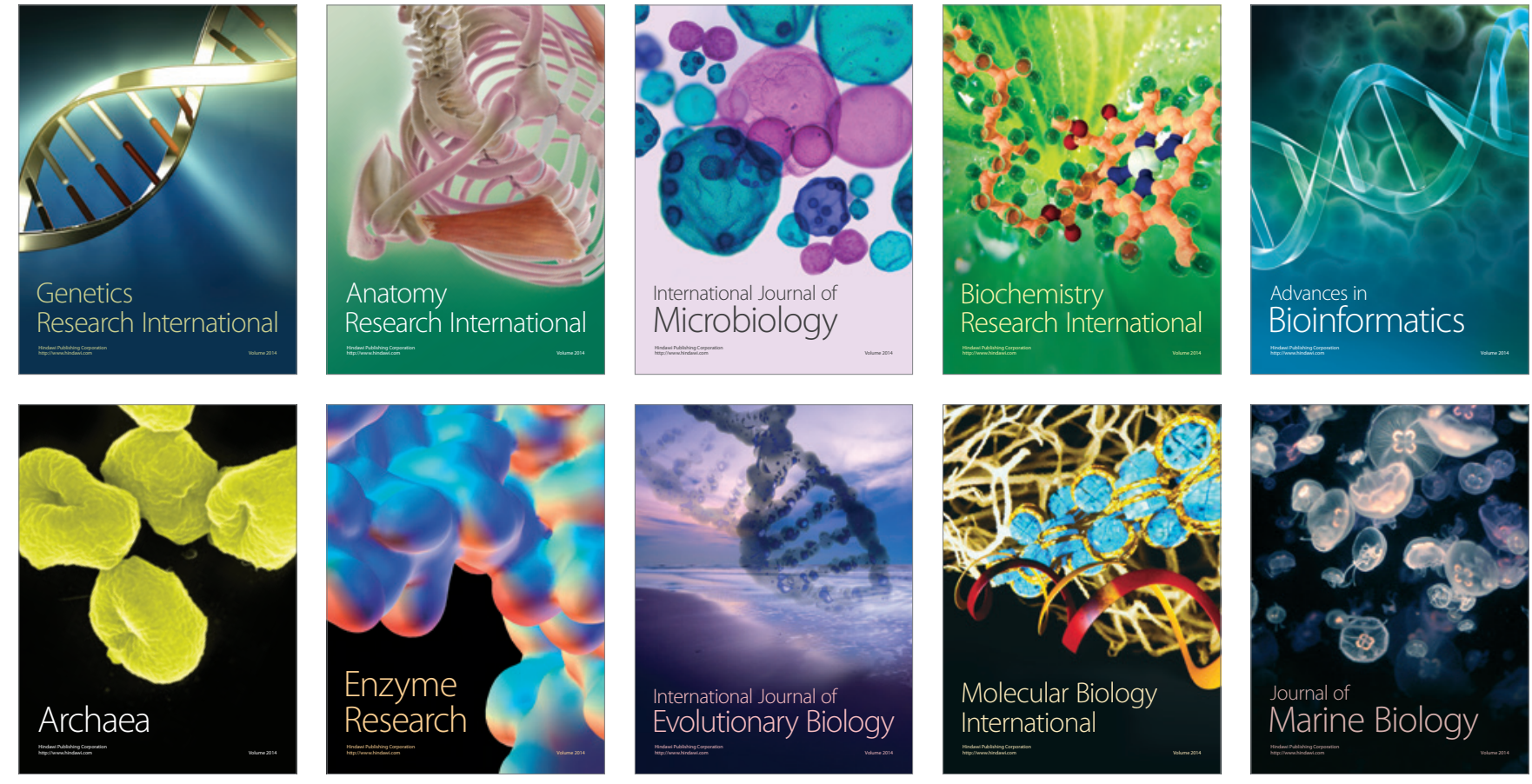